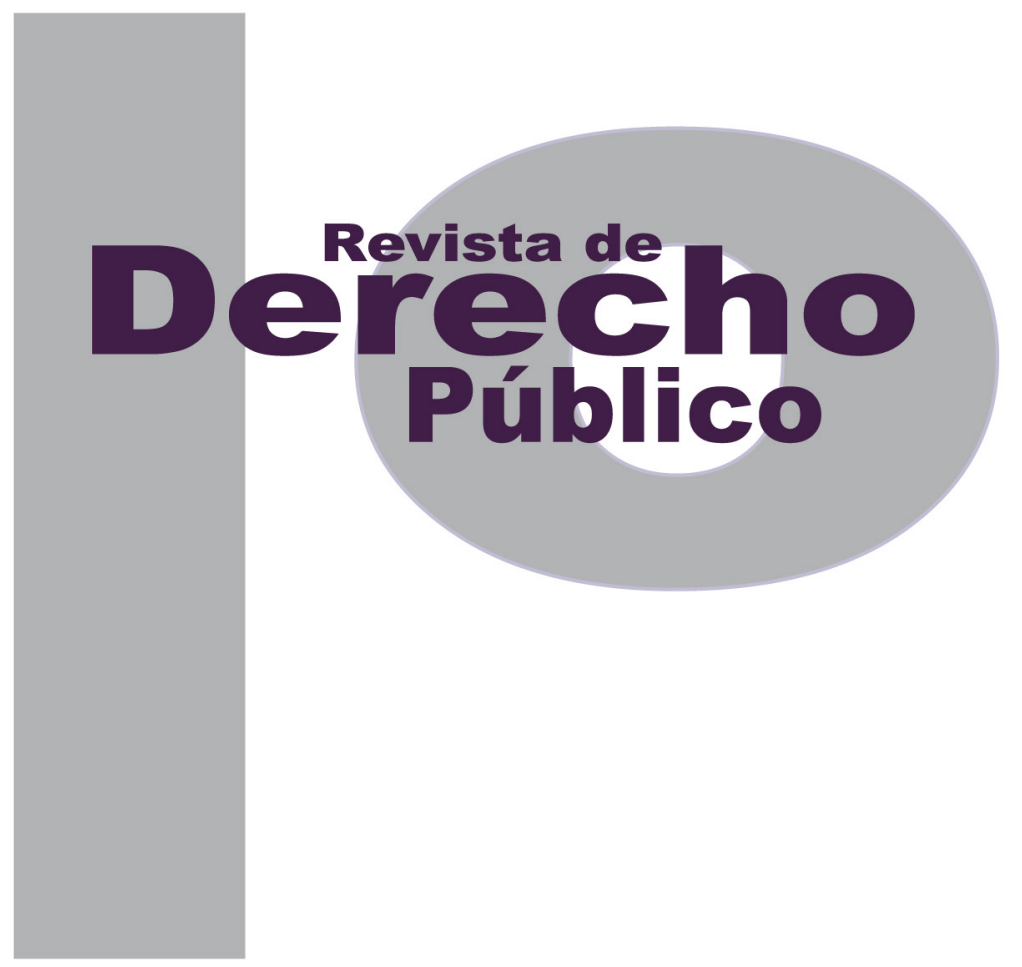

\title{
CONTROVERSIAS JURÍDICAS A LA LUZ DEL AMPARO DE POBREZA EN COLOMBIA. ¿ACCESO A LA JUSTICIA REAL Y EFECTIVO?
}

\author{
LIBARDO QUINTERO SALAZAR
}

\section{Artículo de reflexión}

DOI: http://dx.doi.org/10.15425/redepub.36.2016.09

\author{
Universidad de los Andes \\ Facultad de Derecho \\ Rev. derecho publico No. 36 \\ enero - junio de 2016. e-ISSN 1909-7778
}




\title{
Controversias jurídicas a la luz del amparo de pobreza en Colombia. ¿Acceso a la justicia real y efectivo?
}

\section{Resumen}

Por medio de este artículo se pretende generar algunas discusiones en torno a la figura del amparo de pobreza. En teoría, este instituto jurídico regulado por la ley procesal tiene como finalidad garantizar que las personas de escasos recursos económicos puedan acceder a la administración de justicia sin ningún contratiempo, con ocasión de una situación particular. No obstante, pese a esa finalidad, dicho beneficio puede ser insuficiente para garantizar un adecuado acceso a la justicia debido a que, por un lado, plantea problemas de estructura legal, tales como: i) la deficiente definición de qué se entiende por pobre, ii) la aparente idea conceptual de que las personas jurídicas no pueden solicitar el beneficio y iii) la falta de claridad acerca de la prueba a través de la cual se determina la situación de "pobreza"; y por otro, genera dificultades de aplicación fáctica, tales como: i) falta de inversión de recursos por parte del Estado con el fin de materializarla de forma efectiva, ii) el abogado de oficio, uno de los privilegios que puede otorgar la figura, tiene escasa regulación, ninguna vigilancia institucional organizada para su actuación, y es difícil garantizar su amparo por falta de abogados que ejerzan permanentemente en zonas apartadas del país.

Palabras clave: amparo de pobreza, acceso a la justicia, igualdad procesal, prueba de la calidad de pobre, beneficios económicos, abogado de oficio.

\section{Legal controversies regarding the judicial poverty subsidy in Colombia: a real and effective access to justice?}

\begin{abstract}
This paper analyses the judicial poverty subsidy in Colombia. In paper, such institution aims to guarantee the access to justice of those people that cannot afford legal defense. However, it is argued that it is insufficient to satisfy such objective. On the one hand, it has legal design problems, such as i) the precarious definition of what it means to be poor, ii) the denial of the subsidy to legal persons, and iii) the confusion regarding how to prove the situation of "poverty". On the other hand, there are practical application problems, such as i) the lack of investment to materialize the subsidy and ii) the scarce regulation and institutional surveillance of poverty lawyers, as well as their non-existence on the margins of Colombia.
\end{abstract}

Key words: Judicial poverty subsidy; access to justice; procedural equality; prove of poverty; economic subsidies; poverty lawyer.

\section{Controvérsias jurídicas à luz do amparo de pobreza na Colômbia. Acesso à justiça real e efetiva?}

\section{Resumo}

Por meio deste artigo se pretende gerar algumas discussões em torno à figura do amparo de pobreza. Em teoria, este instituto jurídico regulado pela lei processual tem como finalidade garantir que as pessoas de escassos recursos econômicos possam ter acesso à administração de justiça sem nenhum contratempo, com ocasião de uma situação particular. Não obstante, pese a essa finalidade, dito benefício pode ser insuficiente para garantir um acesso adequado à justiça devido a que, por um lado, apresenta problemas de estrutura legal, tais como: i) a deficiente definição do que se entende por pobre, ii) a aparente ideia conceitual de que as pessoas jurídicas não podem solicitar o benefício e iii) a falta de claridade acerca da prova através da qual se determina a situação de "pobreza"; e por outro, gera dificuldades de aplicação fática, tais como: i) falta de investimento de recursos por parte do Estado com o fim de materializá-la de forma efetiva, ii) o advogado de ofício, um dos privilégios que pode outorgar a figura, tem escassa regulação, nenhuma vigilância institucional organizada para sua atuação, e é difícil garantir seu amparo por falta de advogados que exerçam permanentemente em zonas apartadas do país.

Palavras-chave: amparo de pobreza, acesso à justiça, igualdade processual, prova da qualidade de pobre, benefícios econômicos, advogado de ofício. 


\title{
Controversias jurídicas a la luz del amparo de pobreza en Colombia. ¿Acceso a la justicia real y efectivo?*
}

\author{
LIBARDO QUINTERO SALAZAR **
}

\begin{abstract}
SUMARIO
Introducción - I. EL DERECHO DE ACCESO A LA JUSTICIA - II. EL DERECHO A LA IGUALDAD - III. PROBLEMAS DE ESTRUCTURA LEGAL Y DE APLICACIÓN FÁCTICA EN EL AMPARO DE POBREZA - A. El concepto de pobre - B. La prueba de la calidad de pobre - C. Los beneficios económicos - D. El abogado de oficio - IV. CONCLUSIONES - Referencias.
\end{abstract}

* Cómo citar este artículo: Quintero Salazar, L. (Junio, 2016). Controversias jurídicas a la luz del amparo de pobreza en Colombia. ¿Acceso a la justicia real y efectivo? Revista de Derecho Público, (36). Universidad de los Andes (Colombia). http://dx.doi. org/10.15425/redepub.36.2016.09

Escrito derivado del proyecto de investigación en curso denominado: "Eficacia del amparo de pobreza como mecanismo de acceso a la justicia de las personas de escasos recursos, en los juzgados del circuito del oriente antioqueño", financiado por la Facultad de Derecho e inscrito en la Dirección de Investigación y Desarrollo de la Universidad Católica de Oriente.

** Abogado de la Universidad Católica de Oriente, especialista en Derecho Comercial de la Universidad Pontificia Bolivariana, magíster en Derecho Privado de la Universidad de Salamanca-España y maestrando en Derecho Procesal, Universidad de Medellín. Docente investigador del grupo de investigaciones jurídicas Línea Justicia y Sociedad, de la Facultad de Derecho de la Universidad Católica de Oriente (Rionegro, Colombia). Correo: Iquintero@uco.edu.co 
Introducción

En Colombia, uno de los desarrollos prácticos para garantizar el acceso a la justicia de las personas de escasos recursos económicos es el amparo de pobreza. Por medio de dicha figura, aquellas personas que no se hallen en capacidad de atender los gastos del proceso sin menoscabo de lo necesario para su propia subsistencia y la de las personas a quienes por ley deben alimentos, pueden ser beneficiadas con prerrogativas básicamente de carácter económico.

El amparo de pobreza es una institución relativamente antigua, que ha permanecido invariable de manera sustancial en el Código de Procedimiento Civil colombiano desde los años setenta. El actual Código General del Proceso (CGP), expedido en el 2012, tampoco se ocupó de esta para hacer reformas sustanciales, apenas si acaso amplió unos pocos conceptos, dejando de lado una oportunidad histórica para haberla regulado con mayor amplitud y claridad, y haber tomado medidas para hacerla efectiva.

Hoy en día este instituto tiene grandes vacíos que pudieron haberse tratado, como por ejemplo, el ampliar los parámetros para determinar el estado de pobreza, pues la redacción de la norma da a entender erróneamente que para obtener su beneficio, casi que se tiene que estar en situación de indigencia. Igualmente, tal como está actualmente estructurada la norma, no hay obligación de aportar ni una mínima prueba para comprobar la situación de pobre- za, propiciando su solicitud desmedida y en muchas ocasiones sin causa justificante. Esta situación no es pacífica a nivel de las altas Cortes, a juzgar por sus variadas interpretaciones.

También, aunque la norma establece la exoneración de ciertos gastos, como por ejemplo la de los honorarios de los auxiliares de la justicia, no ocurre lo mismo con algunas pruebas, como la pericia, que demandan costos propios que no son suplidos por el Estado, pues no existe un rubro presupuestal para ello. En este último caso, los gastos de la pericia pueden quedar a cargo del amparado, y si este no puede asumirlos solo le quedan dos opciones: renunciar a las pruebas que necesita y como consecuencia desistir de continuar con el proceso, o perder el proceso por la importancia que puedan tener las pruebas para la litis.

Por otro lado, se echa de menos la regulación sobre el abogado de oficio, pues no hay controles ni parámetros claros para su ejercicio, para su elección ni para su vigilancia, por lo que hubiera sido pertinente la creación de una figura similar a la de la defensoría pública en materia penal y la institucionalidad que ello implica.

Así las cosas, por medio de este escrito se pretende generar una discusión que pueda ser provechosa, en torno a si realmente la figura del amparo de pobreza, tal como hoy funciona, tiene la capacidad de lograr el efecto deseado o esperado con ella y, por ende, beneficiar a las personas de escasos recursos que actúan como partes en un proceso judicial. En ese orden de ideas, no encontrará el lector solu- 
ciones categóricas a las problemáticas planteadas, pero sí elementos para participar en la discusión respecto al cambio, por intermedio de pequeñas reflexiones alrededor de una institución tan importante para los ciudadanos colombianos, especialmente para aquellos de escasos recursos, a quienes acudir a un proceso judicial se les vuelve en muchísimas ocasiones una necesidad tan fundamental como cualquier servicio público.

El artículo se desarrolla de la siguiente manera: se tocan primeramente y de manera general los temas concernientes al derecho al acceso a la justicia y a la igualdad, seguidamente se hace un estudio particular de la figura del amparo de pobreza en los términos referidos, apoyado en la jurisprudencia patria, y finalmente se presentan unas conclusiones en las que se precisan ciertos aspectos y se sugieren algunas soluciones.

\section{EL DERECHO DE ACCESO A LA JUSTICIA}

Para comenzar, es importante hacer referencia al derecho de acceso a la justicia, particularmente desde el punto de vista de su consagración legal en el ámbito internacional en la Convención Interamericana sobre Derechos Humanos, y en el ordenamiento nacional a partir de lo que pregona nuestra Constitución política. Referencias necesarias en la medida que se trata de las normas rectoras de cualquier institución jurídica que pretenda garantizar este derecho, y en particular para el encua- dre del amparo de pobreza como una de las figuras encargadas de concretizarlo.

Se ha entendido por derecho de acceso a la justicia, la posibilidad que tiene todo ciudadano, sin importar su condición económica o social, de acceder al aparato jurisdiccional y resolver sus conflictos. Pero acceder también significa que efectivamente se satisfagan las pretensiones que invocan los ciudadanos. Hoy en día, en el campo de la administración de justicia, "se define la vigencia de los derechos fundamentales en las sociedades contemporáneas, donde se prueba si las libertades y garantías enunciadas en los diferentes instrumentos de derecho internacional tienen o no aplicación en los ámbitos internos" (Ventura Robles, 2015, p. 3).

A nivel internacional (con aplicación en nuestro país por ratificación de tratados), el derecho de acceso a la justicia se configura en una garantía fundamental, reconocida por la Convención Americana sobre Derechos Humanos (Convención Americana) en los artículos 8 y 25; también en el artículo XVIII de la Declaración Americana de los Derechos y Deberes del Hombre. A su vez, el artículo 8.1 del Pacto de San José de Costa Rica estipula el derecho de toda persona a ser escuchada por un juez, en un tiempo razonable para la determinación de sus derechos en cualquier área del derecho; y el artículo 25 de la Convención Americana dispone que toda persona tiene derecho a un recurso sencillo, efectivo y rápido para la protección de sus derechos, y compromete al Estado a garantizarlos, desarrollando posibilidades de recurso judicial. 
En ese sentido la jurisprudencia de la Corte Interamericana de Derechos Humanos (Corte IDH) ha dicho en la sentencia del caso Baldeón García vs. Perú, que "no basta con la existencia formal de los recursos, sino que estos deben ser efectivos, es decir, deben ser capaces de producir resultados o respuestas a las violaciones de derechos" (2006).

Se despliega así el deber que tienen los Estados de no imponer trabas para que las personas puedan acceder a la justicia, por lo que cualquier medida que imponga costos 0 dificulte de alguna forma el acceso de los individuos a los jueces y tribunales, y no esté justificada por las razonables necesidades de la administración de justicia, en palabras de la Corte IDH debe entenderse contraria a las anteriores disposiciones (caso Cantos vs. Argentina, 2002).

De igual forma, en la medida que los obstáculos sean económicos, el Estado debe promover iniciativas, aun con la ayuda de la sociedad civil, que busquen aliviar la gran carga procesal existente y colaborar en la solución de los conflictos que se presenten sobre todo en zonas rurales y alejadas de los centros urbanos. En tal sentido, se ha fijado para los Estados la obligación de proveer servicios gratuitos a las personas de escasos recursos, a fin de evitar la vulneración de derechos y la protección judicial efectiva (Instituto de Defensa Legal de Perú et al., 2008). Pero esas iniciativas deben concretarse en resultados efectivos, que puedan producir los efectos por ellas queridos.
A nivel nacional, la Constitución Política colombiana en su artículo 229 pregona: "Se garantiza el derecho de toda persona para acceder a la administración de justicia". Y como desarrollo del anterior precepto constitucional tenemos igualmente el artículo 2 de la Ley 270 de 1996, que manifiesta: "El Estado garantiza el acceso de todos los asociados a la Administración de Justicia. Será de su cargo el amparo de pobreza y el servicio de defensoría pública. En cada municipio habrá como mínimo un defensor público". [Cursivas fuera de texto].

La Corte Constitucional (Sentencia T268/ 1996, A. Barrera) ha sostenido que el derecho a acceder a la justicia es fundamental, pues forma parte del núcleo esencial del derecho al debido proceso, como quiera que "no es posible asegurar el cumplimiento de las garantías sustanciales y de las formas procesales establecidas por el legislador sin que se garantice adecuadamente dicho acceso." Lo que quiso el constituyente de 1991 al contemplar el artículo 229 de la Constitución Política fue, precisamente, que todas las personas puedan acceder al aparato jurisdiccional para invocar la protección de sus derechos por medio de una tutela judicial efectiva. Y la misma Corte Constitucional en la Sentencia T-173/1993 (J. Hernández) explica que este derecho

no solo se logra con la simple solicitud o planteamiento de las pretensiones procesales ante las respectivas instancias judiciales; por el contrario, el acceso a la administración de justicia debe ser efectivo, lo cual se logra cuando, dentro de determinadas circunstan- 
cias y con arreglo a la ley, el juez garantiza una igualdad a las partes, analiza las pruebas, llega a un libre convencimiento, aplica la Constitución y la ley y, si es el caso proclama la vigencia y la realización de los derechos amenazados o vulnerados.

Lo anterior implica que las situaciones que relativicen o imposibiliten totalmente ese derecho son susceptibles de ser tutelables, al quebrantar tal derecho fundamental, aunque el derecho al acceso a la justicia no se encuentre dentro del capítulo constitucional de los derechos fundamentales.

\section{EL DERECHO A LA IGUALDAD}

El derecho a la igualdad es considerado un derecho fundamental y su reconocimiento normativo se encuentra a nivel internacional y nacional. Todos los instrumentos de protección parten del principio genérico: la no discriminación por cualquier razón social, cultural o económica.

El artículo 7 de la Declaración Universal de los Derechos Humanos señala: “Todos son iguales ante la ley y tienen, sin distinción, derecho a igual protección de la ley. Todos tienen derecho igual a protección contra toda discriminación que infrinja esta Declaración y contra toda provocación a tal discriminación".

El artículo 13 de nuestra Carta Política consagra como principio y derecho fundamental la igualdad en los siguientes términos:
El Estado promoverá las condiciones para que la igualdad sea real y efectiva y adoptará medidas en favor de grupos discriminados o marginados.

El Estado protegerá especialmente a aquellas personas que por su condición económica, física o mental, se encuentren en circunstancia de debilidad manifiesta y sancionará los abusos o maltratos que contra ellas se cometan. [Cursivas fuera de texto].

Por lo tanto, entendemos por tal derecho el trato igual que debemos tener frente a los iguales, ante la ley y ante las entidades públicas, de una manera que sea real y efectiva, y con especial protección de las personas más débiles en una situación determinada, o como lo ha dicho la Corte Constitucional al referirse a la aplicación del principio de igualdad:

Tiene como finalidad determinar, en cada caso concreto, si existe discriminación en relación con una de las situaciones o personas puestas en plano de comparación, entendida la discriminación como el trato diferente a situaciones iguales o simplemente el trato diferente que no tiene justificación. (CConst., T-861/99, C. Gaviria).

Para efectos de lo que nos interesa, el artículo 13 constitucional se refiere a diferentes formas de no discriminación, entre las cuales se encuentra la no discriminación por la capacidad económica de las personas. Por citar un ejemplo: en el pasado fue común restringir derechos a los ciudadanos por su calidad 
de pobres, inclusive en la propia Constitución. En la historia de las constituciones políticas se observa que desde 1821 los ciudadanos no podían votar si no tenían determinado patrimonio; dichas limitaciones se mantuvieron hasta el siglo XX con la Constitución de 1886, que para que una persona pudiera votar por representantes a la Cámara, exigía, además de saber leer y escribir, que tuviera una renta anual de quinientos pesos, o propiedad inmueble por valor de mil quinientos pesos (artículo 173).

Nuestro estatuto procesal civil, artículo 4, establece como principio, ya concretizado al proceso jurisdiccional civil, la igualdad de las partes ante la ley procesal, con lo que se busca en palabras del profesor Devis Echandía (1978), que en la práctica verdaderamente se dé una igualdad real y no teórica, que le aporte al proceso un contenido social, con mayores posibilidades de que exista una justicia verdadera como instrumento eficaz en pro del mantenimiento de la paz social, y que procure hacer efectiva la igualdad de las partes ante el proceso, protegiendo al débil que para él es siempre la parte más pobre.

Con todo, el reconocimiento del derecho a la igualdad ante la ley implica que no solo basta con un reconocimiento de derechos, sino que debe conciliarse su aplicación en la realidad; hoy por hoy, el que no existan desigualdades a nivel formal en la ley no significa que no hayan diferencias en la práctica al momento de darle aplicación en los casos concretos.

\section{PROBLEMAS DE ESTRUCTURA LEGAL Y DE APLICACIÓN FÁCTICA EN EL AMPARO DE POBREZA}

Ya manifestaba cómo el artículo 13 de la Constitución Política reconoce que las condiciones económicas precarias pueden ser constitutivas de desigualdad, por lo que en materia de acceso a la justicia el legislador colombiano, para equilibrar el desbalance que se pudiera generar dentro un proceso judicial por esa razón, estableció el amparo de pobreza.

La institución como tal se encuentra regulada en los artículos 151 a 158 del CGP; en ellos básicamente se reproducen los alcances de legislaciones anteriores, como quien dice, por décadas ha permanecido invariable, lo que evidencia el poco interés en incluir cambios sustanciales que puedan mejorarla en la práctica.

Propiamente dicho, el amparo de pobreza es un beneficio que la ley otorga a la parte que carece de recursos económicos suficientes para atender los gastos del proceso, al eximírsele de gastos propios de él, pero también, dándole la posibilidad de la asistencia de un abogado de oficio. En palabras de la Corte Constitucional:

El amparo de pobreza es un instituto procesal que busca garantizar la igualdad real de las partes durante el desarrollo del proceso, permitiendo a aquella que por excepción se encuentre en una situación económica considerablemente difícil, ser válidamente exonerada de la carga procesal de asumir ciertos costos, que inevitablemente se presentan 
durante el transcurso del proceso. Se trata de que, aun en presencia de situaciones extremas, el interviniente no se vea forzado a escoger entre atender su congrua subsistencia y la de a quienes por ley debe alimentos, o sufragar los gastos y erogaciones que se deriven del proceso en el que tiene legítimo interés. (CConst., T-114/07, N. Pinilla).

En Colombia, aunque se predique la gratuidad de la justicia, es bien sabido que existen gastos inherentes al trámite de un proceso, por lo que en muchos lugares de nuestro país la falta de recursos podría menguar el ejercicio de un derecho ante la justicia.

A continuación haré un repaso por los postulados básicos de la figura, para ir concluyendo en cada uno lo que a mi parecer no funciona, le hace falta o no es exigible en la vivencia real.

\section{A. El concepto de pobre}

Para comenzar: ¿Qué se entiende por pobre? Dicho concepto lo encierra la misma institución “amparo de pobreza”. Según el Diccionario de la lengua española, pobre puede ser: (1) necesitado, que no tiene lo necesario para vivir; (2) escaso, insuficiente; inclusive, (3) humilde, de poco valor o entidad; (4) infeliz desdichado y triste, entre otras acepciones. De entrada, desde un punto de vista jurídico, es incorrecto hablar de "pobreza", por las consideraciones equívocas a que puede llevar un concepto con tan disímiles definiciones. Además, cualquiera podría creer, erróneamente, que para hacerse beneficiario del amparo tiene que estar en estado de indigencia.

Igualmente, dicho sea de paso, aunque sea un argumento más sicológico y social que jurídico, el concepto de "pobre" al contener términos peyorativos (humilde, de poco valor, infeliz, desdichado y triste) genera una idea desfavorable y ofensiva para quien desea obtener el beneficio del amparo. Esto, aunado a la carga emotiva de mendigar al Estado su ayuda, muestra la conveniencia de cambiarle el nombre a la figura por otro que tenga mayor sentido jurídico y resulte menos molesto (López Blanco, 2005). En otros países como España, Argentina y Guatemala, a la misma institución se le llama "beneficio de litigar sin gastos".

En su definición el legislador matiza el concepto y para efectos del proceso judicial considera pobre a la "persona que no se halle en capacidad de atender los gastos del proceso sin menoscabo de lo necesario para su propia subsistencia y la de las personas a quienes por ley debe alimentos". Pero dicho matiz deja dos inconvenientes: i) restringe el concepto de pobre desde el punto de vista jurídico (sin menoscabo de lo necesario para su propia subsistencia y la de su familia), y ii) aparentemente deja por fuera de dicho beneficio a las personas jurídicas.

Frente al primero, hubiese sido más conveniente dejar librada a la apreciación judicial la determinación de insuficiencia de los recursos del interesado para afrontar los gastos del proceso, en cada caso concreto. Pobre, en el 
sentido legal, es aquel que aunque tenga lo indispensable para vivir, no tiene para litigar (Palacio, 1977). Este concepto es muy importante, pues pobreza en este contexto no significa indigencia extrema, sino que quien solicite el beneficio no tenga dinero para afrontar los gastos del juicio.

El solicitante deberá demostrar la carencia de recursos y la imposibilidad de obtenerlos, y por ende, que no puede afrontar las erogaciones que demande el proceso de que se trate. En otras palabras, debe existir una relación directa entre el monto del proceso y los recursos que se tengan, por lo que inclusive personas que se encuentran dentro de la llamada "clase media" podrían solicitar el beneficio.

En Colombia, según un cálculo de la Universidad de los Andes, una familia de cuatro personas en la clase vulnerable tiene hoy ingresos de entre 558.000 y 1.400 .000 pesos mensuales. Y en la clase media, la misma familia gana entre 1.400 .000 y 7.000.000 (Semana, 2015). En este último caso, pensemos por ejemplo en una persona de clase media que pertenece a un núcleo familiar cuyos recursos ascienden a 1.500.000 pesos mensuales y afronta un juicio por 50.000 .000 de pesos. Es obvio que los recursos familiares para atender las necesidades básicas pueden estar en peligro.

Frente a lo segundo, una primera mirada a la redacción del artículo 154 del CGP hace pen- sar que el beneficio solo puede ser concedido a personas naturales, pues para poderlo solicitar se debe estar bajo el supuesto de que no pueda atender los gastos del proceso sin menoscabo de su propia subsistencia y la de las personas a quienes por ley debe alimentos. En principio, técnicamente, las personas jurídicas no encajarían dentro de esa noción (Morales Molina, 1991). Cuestión que ha sido controvertida especialmente a nivel de las altas Cortes.

La jurisprudencia del Consejo de Estado, ${ }^{1}$ por ejemplo, en principio se había mostrado reservada al momento de conceder dicho beneficio a personas jurídicas. Sin embargo, en una providencia (CE, Cuarta, 1 feb. 2002, J. Ángel) en la que decidía un recurso de apelación, dijo que no era procedente el amparo para las personas jurídicas.

Los hechos fueron los siguientes: la sociedad Distribuidora F. y F. de Colombia Ltda. instauró demanda de nulidad y restablecimiento del derecho contra los actos administrativos que le determinaron oficialmente el impuesto sobre la renta por el año gravable de 1995. El Tribunal admitió la demanda y ordenó a la demandante que dentro del término de 15 días prestara caución equivalente al $20 \%$ de la suma discutida. Dicha sociedad, con apoyo en los artículos 13 de la Constitución y 160 del Código de Procedimiento Civil (CPC), solicitó al Tribunal concederle amparo de pobreza por hallarse en incapacidad de atender los gastos del proceso,

1. Por remisión del Código Contencioso Administrativo, son aplicables las reglas del amparo de pobreza contempladas en el Código de Procedimiento Civil y el Código General del Proceso. 
pues los socios de la sociedad Distribuidora F. y F. de Colombia Ltda., en liquidación, decretaron su disolución al verse imposibilitados económicamente para desarrollar el objeto social, y la situación de la empresa no les permitía prestar dicha caución. El tribunal negó la solicitud.

El Consejo de Estado, en esa ocasión, dijo:

Es claro que en este caso no puede otorgarse amparo de pobreza, como quiera que el citado beneficio está previsto expresamente para las personas naturales y no para las personas jurídicas, ya que el artículo 160 del C. de P.C. se refiere como sujeto del amparo a quien no se halle en capacidad de atender los gastos del proceso sin menoscabo de lo necesario para su propia subsistencia y la de las personas a quienes por ley debe alimentos, expresiones todas aplicables solamente a las personas naturales y no a las personas jurídicas, a quienes excluye de tal beneficio.

El criterio anterior venía siendo expresado por esa Corporación, entre otras providencias, en las de los años 1993 (exp. 4717) y 1999 (exp. 5506). Afortunadamente, con posterioridad, el mismo Consejo de Estado (Contencioso, 3 may. 2007, L. López), sumó una nueva posición donde acepta que las personas jurídicas eventualmente puedan solicitar dicho beneficio y que este puede ser otorgado:

Conforme a lo expuesto por la Sala, resulta procedente darle un alcance amplio a la norma, adecuándola a las condiciones propias de las personas jurídicas, lo cual no permite afirmar de manera categórica que tales entes se encuentran excluidos del beneficio previsto en el artículo 160 del C.P.C. En todo caso, la posibilidad de que las personas jurídicas accedan al amparo de pobreza es excepcional, debiéndose valorar en cada situación particular su verdadera situación financiera conforme a los medios probatorios allegados para tal fin.

Con todo, considero que las personas jurídicas pueden solicitar el amparo de pobreza, pues en su condición de personas tienen derecho al acceso efectivo a la administración de justicia y a la igualdad. Y aunque el parámetro de pobreza que trae la ley es restrictivo se debe hacer una interpretación amplia, para entender que aunque la persona jurídica no debe alimentos, sí puede depender de ella el sustento de sus socios, los trabajadores y sus familias. Por lo tanto, una empresa en estado de liquidación como la del ejemplo, o inclusive alguna que pudiera colocarse en situación de insolvencia por los costos que puede ocasionar un proceso judicial, podría ser favorecida con el amparo de pobreza si se llegare a poner en riesgo su subsistencia.

De todas formas, estoy de acuerdo en que en estos casos especiales, y en particular cuando quien solicite el amparo sea una sociedad mercantil, es sano exigir pruebas de la condición de pobreza, pues no sería de recibo que el solo hecho de afirmar estar al borde de un estado de insolvencia o acreditar dicha condición por medio de testigos baste para otorgarle el de- 
precado beneficio. Lo correcto sería estudiar la verdadera situación económica y financiera de la empresa a partir de pruebas propias de estas instituciones, tales como balances, estados contables, pasivos internos y externos, entre otras.

En estos casos se debe ser más riguroso, pues no es lo mismo que quien solicite el amparo sea una sociedad mercantil que tiene claros fines de lucro, y cuyo desenvolvimiento económico y comercial en poco se parece al de una persona natural. Si bien debe darse una interpretación amplia para que las personas jurídicas puedan solicitar el amparo, también se debe ser riguroso al momento de la apreciación de la prueba, para evitar que se rompa la finalidad de la institución (Rodríguez Saiach y Knavs, 2007).

\section{B. La prueba de la calidad de pobre}

En Colombia, para que un solicitante pueda ser beneficiado con el amparo de pobreza, le basta con afirmar que no le es posible litigar sin menoscabo para su propia subsistencia y la de las personas a quienes debe alimentos. Dicha afirmación se entenderá hecha bajo la gravedad de juramento. ${ }^{2}$ En otras palabras, quien solicita el amparo no está en la obligación de aportar prueba alguna de su condición de pobreza, pero sí de decir la verdad:
Razón por la cual no tiene mayor aplicación la posibilidad contemplada en el artículo 162 (hoy artículo 163 CGP) de denegar el amparo e imponer multa de un salario mínimo que allí se prevé, aun cuando debe advertirse que en el caso en que se demuestre que es falso el juramento podrá a más de revocarse el beneficio adelantarse acción penal que entraña el falso juramento. (López Blanco, 2005, p. 454).

Pese a que esa ha sido la premisa general para su otorgamiento, en la jurisprudencia de nuestras Cortes el concepto no ha sido uniforme.

Así, por ejemplo, la Corte Suprema de Justicia ha dicho:

Al respecto, el artículo 160 del Código de Procedimiento Civil, modificado por el Decreto 2282 de 1989 , determina que se concederá el amparo de pobreza "a quien no se halle en capacidad de atender los gastos del proceso sin menoscabo de lo necesario para su propia subsistencia y la de las personas a quienes por ley debe alimentos, salvo cuando pretenda hacer valer un derecho litigioso a título oneroso.

La simple lectura de la norma es suficiente para concluir que no se exige prueba alguna tendiente a demostrar la carencia de medios económicos para atender los gastos del

2. Artículo 152 cGP. El solicitante deberá afirmar bajo juramento que se encuentra en las condiciones previstas en el artículo precedente, y si se trata de demandante que actúe por medio de apoderado, deberá formular al mismo tiempo la demanda en escrito separado. 
proceso, pues basta que tal circunstancia se afirme bajo juramento. (CSJ Penal, 8 jun. 2011, J. Socha).

En una oportunidad anterior, la Corte Constitucional (Sentencia, T-680/07), matizó el concepto pidiendo una prueba mínima:

En resumen, de la jurisprudencia constitucional transcrita esta sala concluye que en punto a la incapacidad económica de las personas, la Corte ha señalado un principio de análisis probatorio que excluye la prueba exhaustiva como medio de convicción de la situación de pobreza del tutelante. La falta de exigencia de una prueba "diabólica" en el contexto de la verificación de la incapacidad económica hace que el juez deba valorar otras circunstancias particulares para deducir la situación material del tutelante. Y aunque la mayoría de la jurisprudencia transcrita analiza el tema desde el punto de vista de acceso a los servicios de salud, es claro que el análisis hecho es perfectamente aplicable en otros escenarios, en donde también pueda discutirse la capacidad económica del individuo como mecanismo para resolver una reclamación o la concesión de un derecho subjetivo.

El Consejo de Estado (Contencioso, 17 abr. 2013, C. Ortiz) ha venido solicitando pruebas para cuando quien pretenda el beneficio de amparo de pobreza sea una persona jurídica. Es de anotar que dicha posición también ha sido manifestada en otra jurisprudencia de la misma entidad, que inclusive ha tenido salva- mentos de voto, estos últimos justificados en que la ley procesal no exige prueba de la calidad de pobreza, ni aun, en el caso de las personas jurídicas. El Consejo de Estado dijo en esa oportunidad:

Ahora bien, para acceder al amparo de pobreza el juez debe examinar en cada caso particular la verdadera situación financiera del demandante, conforme con los medios probatorios allegados para tal fin.

(...) Conforme con lo anterior y revisado el expediente encuentra el Despacho que el apoderado de la parte actora no aporta pruebas suficientes, como lo serían las declaraciones de renta y estados financieros actualizados, pues una copia simple que presentó con corte a diciembre de 2010 del balance general y estado de resultados, no permite concluir que la demandante está en incapacidad de garantizar los resultados del proceso en el evento en que le fuera desfavorable la sentencia.

Otra interpretación, en línea de solicitar prueba para conceder el amparo de pobreza, la hizo de nuevo la Corte Suprema de Justicia, Sala Laboral (8 feb. 2006, I. Vargas). Pero en este caso, para su fundamento, analizó que ello era posible, en la medida que el amparo tiene el carácter de un incidente sobre el que debe aportarse prueba. En esa ocasión frente al amparo de pobreza en procesos laborales dijo:

Si bien es cierto la jurisprudencia de la Sala ha aceptado su procedencia en los procesos 
laborales, también lo es que su concesión no fluye de la simple solicitud formulada bajo juramento por el petente, sobre el entendido que las disposiciones que lo regulan son las correspondientes al trámite incidental consagrado en los artículos 37 y 38 del Código Procesal del Trabajo y de la Seguridad Social, tal y como se dijo en la providencia del 15 de agosto de 2000 radicado 14957 en los siguientes términos:

“Conforme se explicó en auto de 28 de agosto de 1997 (Rad. 9933), por deberse tramitar como incidente la solicitud de amparo debe sujetarse a lo dispuesto en los artículos 37 y 38 del Código Procesal del Trabajo, por lo que "no basta la simple solicitud juramentada sino que es necesario presentar o pedir la práctica de pruebas que ameriten el amparo', lo que en este caso no hizo Jaime García Ríos."

De lo anterior se colige la disparidad de criterios de nuestra jurisprudencia. Eso genera inseguridad jurídica, por lo que el ciudadano no sabrá a ciencia cierta si debe probar de entrada o no, y en qué nivel, la condición de pobreza. Ahora, en muchas ocasiones los criterios de exigencias probatorias, según el esquema actual de la figura, pueden resultar forzados. Así, por ejemplo, en el último extracto jurisprudencial citado de la Sala Laboral de la Corte Suprema de Justicia se fundamenta la presentación de pruebas, al estar atado el amparo de pobreza a una cuestión incidental. Pero ello no siempre es así, en la medida que aun en el área laboral el amparo puede solicitarse antes de presentarse la demanda ${ }^{3} 0$ antes de que inicie el proceso, etapas en que no cabe plantearse cuestiones incidentales, pues los incidentes, precisamente, son accesorios a un proceso.

Con todo, considero que la figura debe cambiar de presupuesto, es decir, presumir de entrada que todo litigante es "rico" mientras no se demuestre lo contrario, o dicho en otras palabras, que se presuma legalmente que todo litigante tiene los suficientes recursos económicos. Hoy en día, la concesión irrestricta de la figura ha llevado a que sea solicitada por personas que no lo necesitan, con la finalidad específica de no ser condenadas en costas, lo que consecuencialmente priva al litigante vencedor del derecho a recuperar los gastos que tuvo que asumir dentro del juicio. Pero más grave aún, puede coadyuvar a la congestión judicial, pues si no hay nada que perder (si pierdo no me condenan en costas), incita a que inclusive puedan ser propuestas ante la justicia causas sin mayor fundamento y seriedad.

Por supuesto, plantearse lo anterior tiene sentido en la medida que la institución se fortalezca desde varios aspectos, entre los que destacan los económicos y administrativos, ${ }^{4}$ pues de lo contrario, en las condiciones actuales,

3. Artículo 152 CGP. "El amparo podrá solicitarse por el presunto demandante antes de la presentación de la demanda, o por cualquiera de las partes durante el curso del proceso."

4. Que tocaremos en los ítems subsiguientes. 
podría convertirse en un obstáculo más de la figura para las personas que verdaderamente lo necesitan.

Cabe preguntarse si demostrar la condición de pobreza para acceder al amparo es excesivo, o en otras palabras, si presumir legalmente que se tienen los recursos económicos para litigar, mientras no se demuestre lo contrario, puede llegar a atentar contra el derecho de acceso a la justicia.

Debo traer a colación la sentencia de constitucionalidad C-388/00 de la Corte Constitucional, por la relación que puede tener con lo inmediatamente expuesto. En esa oportunidad, un ciudadano pretendía que se declarara la inconstitucionalidad de una parte del artículo 155 del Código del Menor (hoy Código de la Infancia y la Adolescencia), que expresaba que para efectos de acreditar el monto de los ingresos de una persona que debe alimentos, cuando no hay alguna forma objetiva para establecerlos, el juez podría presumir que devenga el salario mínimo legal. ${ }^{5}$

El actor consideraba que dicha disposición vulneraba el principio de presunción de inocencia contemplado en el artículo 29 de la Constitución Política, en la medida que dicho artículo venía siendo aplicado para que la Fiscalía, en aquellos casos en que no pudiese establecerse lo que devengaba un imputado por el deli- to de inasistencia alimentaria, acusara bajo la presunción de que ganaba el salario mínimo y que igualmente los jueces tomaran en cuenta dicha presunción a la hora de condenar. También argumentaba que los jueces de familia podrían llegar a declarar una cuota alimentaria que no correspondía con el mismo nivel de ingresos.

La Corte Constitucional declaró exequible la norma, y para ello hizo una clara explicación de las presunciones legales y cómo estas no comprometen el debido proceso. Manifestó entonces:

La existencia de las presunciones legales no compromete, en principio, el derecho al debido proceso. Nada obsta para que el legislador, con el fin de dar seguridad a ciertos estados, situaciones o hechos jurídicamente relevantes y de proteger bienes jurídicos particularmente valiosos, respetando las reglas de la lógica y de la experiencia, establezca presunciones legales. En estos casos, la ley reconoce la existencia empírica de situaciones reiteradas y recurrentes, comúnmente aceptadas, para elevarlas, por razones de equidad, al nivel de presunciones. (C388/00, E. Cifuentes).

Es decir, los dos elementos a tener en cuenta para valorar, es si la presunción legal, por un lado, es razonable y, por el otro, si se justifica para proteger otros derechos valiosos.

5. Art. 155. Cuando no fuere posible acreditar el monto de los ingresos del alimentante, el juez podrá establecerlo tomando en cuenta su patrimonio, posición social, costumbres y en general todos sus antecedentes y circunstancias que sirvan para evaluar su capacidad económica. En todo caso se presumirá que devenga al menos el salario mínimo legal." Resaltado en cursivas lo que se pretendía declarar inexequible. 
Frente a lo primero dijo:

Podría alegarse que una parte importante de la población colombiana que vive por debajo de la línea de pobreza o que carece de un empleo estable se encuentra en una circunstancia diferente a aquella que la disposición demandada presume. En consecuencia, la presunción legal no sería razonable dado que se distancia de las condiciones en las que efectivamente se encuentra un sector considerable de la población a la cual se dirige.

Sin embargo, para que una presunción resulte razonable no es necesario demostrar que la totalidad de los sujetos que puedan eventualmente ser afectados se encuentren en las condiciones de hecho establecidas en la correspondiente disposición. Si ello fuera así, no solo se estaría desvirtuando completamente la naturaleza y el carácter de las presunciones, sino que resultaría francamente imposible o inútil establecer presunciones. (C-388/00, E. Cifuentes).

Frente a lo segundo afirmó:

La presunción establecida en el artículo 155 del Código del Menor puede ser desvirtuada por el deudor. En efecto, dicha disposición no implica una ficción incontrovertible, sino una carga procesal que se impone al alimentante dada la importancia de los derechos de su contraparte en el proceso de alimentos -el menor-, y la desigualdad material que exis- te entre las partes respecto del acceso a la prueba. En este sentido, el sujeto afectado puede utilizar los recursos que estén a su alcance para demostrar que no devenga el salario mínimo legal. Dado que nadie está obligado a lo imposible (CC art. 416), al desvirtuar la presunción, el juez queda obligado a inaplicarla o a relevar al deudor del pago de la cuota fijada en virtud de un patrimonio que no corresponde a su realidad económica. Como lo ha reconocido la Corte, la carencia de recursos económicos impide la exigibilidad de la obligación civil. (C-388/00, E. Cifuentes).

Por lo anterior, opino que para efectos de litigar, presumir que se tienen las condiciones económicas para hacerlo no acarrea cargas que comprometan el acceso a la justicia, por lo que dicha medida resultaría razonable y tendría finalidades provechosas definidas.

De esa forma, toda persona que quiera acceder al amparo de pobreza deberá probar que efectivamente no se encuentra en condiciones de asumir un proceso judicial; esto limitaría en gran medida la solicitud desproporcionada del amparo desincentivando su uso por aquellas personas que no tienen objetivamente cómo probar o que verdaderamente no lo necesitan $y$, además, permitiría un mayor control del juez a la hora de otorgarlo.

Frente a esto último cabe anotar, que según la regulación propia del amparo de pobreza en el CGP, el beneficio puede revocarse si luego de 
ser concedido se logra demostrar que la persona no era pobre. Ahora, lo difícil es cómo saberlo, si en principio no se exige prueba. Además, en el hipotético caso que se supiera, es desgastante acometer el estudio de si era procedente concederlo o no, después de otorgado, contrario a si ese análisis se hubiese hecho desde un principio.

Dicha presunción ayudaría de alguna manera a descongestionar los despachos judiciales y contribuiría al acceso a la justicia de todos los ciudadanos; también permitiría que se beneficien de la figura las personas que verdaderamente lo necesiten.

No se trataría ni siquiera de aportar una "prueba diabólica" para romper la presunción, sino una prueba sumaria. ${ }^{6}$ Por lo tanto, el solicitante, en el ejercicio del derecho a solicitar el amparo de pobreza puede desvirtuar la presunción demostrando, a partir de una prueba sumaria, que no se halla en capacidad de atender los posibles gastos que le pueda acarrear el proceso judicial. Considero, por ejemplo, que se podrían aportar como pruebas en el caso de personas naturales: certificado del SISBEN (Sistema de Identificación de Potenciales Beneficiarios de Programas Sociales), colillas de pago salarial, certificados bancarios que acrediten deudas, testigos, etc. Para las personas jurídicas: balances, estados contables, pasivos internos y externos, entre otras, pues como lo había manifestado antes, con estas las pruebas deben ser más estrictas y más específicas.

Finalmente, frente a este tema, considero que deben existir personas jurídicas y naturales que puedan acceder al amparo por derecho propio y sin necesidad de acreditar prueba alguna, como sería el caso de sociedades civiles dedicadas a la beneficencia pública y de la comunidad (p. ej. asociaciones de consumidores, de víctimas, asociaciones para la protección contra la violencia de género, por citar algunas), personas en situación de desplazamiento, madres cabeza de familia, etc.

\section{Los beneficios económicos}

De conformidad con el artículo 154 del CGP, el amparado por pobre no estará obligado a prestar cauciones procesales ni a pagar expensas, honorarios de auxiliares de la justicia u otros gastos de la actuación, y no será condenado en costas.

Frente al no pago de cauciones y de costas, es cierto que ha funcionado y ha generado un gran alivio a las personas de escasos recursos que se han intervenido en un proceso judicial.

6. “Uno de los principios de la prueba judicial es el principio de contradicción, en virtud del cual, ella no puede ser apreciada si no se ha celebrado con audiencia, con conocimiento de la contraparte, es decir, la prueba no contradicha carece de valor. Sin embargo, en algunos casos el legislador se lo da a pruebas que no han cumplido con el principio indicado... La Corte, en sentencia del 29 de julio de 1980, sostuvo: el carácter sumario de una prueba dice relación no tanto a su poder demostrativo, sino a la circunstancia de no haber sido contradicha. Se opone, por tanto, a la controvertida, es decir, a la que ha sido practicada con citación y audiencia de la parte contra la cual se pretende hacer valer." (Parra Quijano, 2004). 
Y esto ha funcionado porque prácticamente se trata de gastos que ya ha asumido el contrincante vencedor ${ }^{7}$ (en el caso de las costas), y en momento alguno el Estado de su erario público.

Pero el asunto cambia cuando hablamos de costos relacionados con los honorarios de los auxiliares de la justicia y los gastos de la pericia (que se supone están cubiertos con el amparo de pobreza). Como se puede entrever, la única prueba que quizás pueda tener un costo elevado en un proceso judicial es, sin duda, la prueba pericial. Podríamos pensar en el sinnúmero de procesos donde esta prueba es fundamental para el buen esclarecimiento de los hechos, por ejemplo, en una prueba grafológica para determinar la falsedad de unos documentos presuntamente falsos, el avalúo de un bien, etc.

Frente al tema de los honorarios de los peritos cuando se ha solicitado el amparo, el legislador ha previsto dicha situación estableciendo que el juez fijará los honorarios de los auxiliares de la justicia (por ejemplo un perito) y serán pagados por la parte contraria dentro de la condena en costas. Pero esto solo soluciona una situación y deja en blanco otras. Así, los honorarios solo se le fijarán al perito si la contraparte del amparado por pobre pierde el proceso y es condenado en costas, pero si por ejemplo es el amparado quien pierde el proceso o ambas partes son beneficiarias del amparo (lo que es posible), ¿quién pagaría los honorarios del perito? En este caso los asume el perito ya que no existe en Colombia un rubro presupuestal dentro de la administración de justicia que asuma tal costo. La pregunta es si es justo que el Estado los traslade a los mismos ciudadanos.

Igualmente, debemos diferenciar entre la pericia como prueba a practicar bajo la fuerza humana de trabajo del perito, y las costas de la pericia. En este último caso se habla de aquellos gastos en los que se puede incurrir para la práctica de la pericia, como podrían ser por ejemplo los gastos de desplazamiento a otras regiones, gastos de estadía, gastos en materiales propios para poder efectuar la prueba, etc., que como veremos no están previstos en el amparo de pobreza. Podemos asumir que el perito acoja el llamado a la caridad por parte del Estado y no cobre por sus servicios, pero definitivamente existen cargas económicas que no está obligado a soportar.

También es importante recalcar que el artículo 230 CGP, que habla del dictamen pericial decretado de oficio, ordena al perito rendir dictamen así no se hayan consignado los honorarios y gastos fijados provisionalmente (estos últimos se considerarían gastos de la pericia) so pena de sanción, lo que implica que en principio deba él sufragarlos. Pese a lo anterior no puede entenderse que debe asumirlos de forma definitiva, en la medida que con posterioridad deberán pagarlos las partes por igual, sin

7. Ya decía cómo la falta de exigencia de prueba puede propiciar la solicitud del beneficio con la intención específica de que no se condene en costas, en detrimento de los derechos de la parte vencedora en el juicio. 
perjuicio de lo que se resuelva sobre costas, de conformidad con lo establecido en los artículos 169 y 363 CGP. 0 dicho en otras palabras, el artículo 230 del CGP hace referencia a que el perito asume los gastos, pero bajo el entendido de que luego deban ser compensados por las partes según se concluye de los artículos 169 y 363 ya citados. Pero de nuevo el problema surge: cuando en el proceso judicial donde se decreta un peritaje de oficio existan amparados por pobres y estos no puedan pagar ni antes ni después los gastos de la pericia, ¿podría el perito negarse a rendir dictamen?, y si se niega, ¿podría ser sancionado aunque se supiera que finalmente no se le compensarán posteriormente dichos gastos?, ¿debe asumirlos sin más, sin importar el valor de estos, y aun así considerarse una carga lícita y proporcionada, además de no percibir eventualmente honorarios por su trabajo?

Lo anterior demuestra cómo se pueden estar imponiendo cargas desproporcionadas a dichos auxiliares de la justicia, y cómo ante una justa negativa que genere controversia en el proceso, eventualmente puede llegar a incidir negativamente en el reclamo de los derechos del amparado por pobre.

En contraste, también interesa señalar cómo la falta de recursos económicos para atender los gastos de la pericia puede afectar el derecho de defensa y con ello el acceso efectivo a la justicia.

Para una mejor claridad veamos un ejemplo de la jurisprudencia, concretamente una acción de revisión de un fallo de tutela que llegó a la Corte Constitucional (Sentencia T-356/09), con los siguientes hechos: en un juzgado de familia de la ciudad de Medellín se adelantaba un proceso de filiación extramatrimonial a favor de un niño, con respecto a su padre ya fallecido. Para determinar la paternidad alegada se ordenó reconstruir el perfil genético, por lo que se ofició al Instituto Nacional de Medicina Legal y Ciencias Forences (INMLCF) para la realización del procedimiento ante el cementerio Jardines de la Fe, en Copacabana-Antioquia. Para la época el cementerio exigía la suma de 795.000 pesos por concepto de los gastos del procedimiento de exhumación (Ios que vendrían siendo los llamados gastos de la pericia).

Como la madre del niño no tenía los recursos económicos para costear tales gastos, instauró una acción de tutela contra el cementerio, buscando que se ampararan los derechos fundamentales del niño, entre ellos el derecho a la vida, la integridad física, la seguridad social y el derecho a una familia, etc.

En primera y segunda instancia la tutela fue denegada bajo el argumento que esos gastos no los cubría el amparo de pobreza, y que la entidad accionada no podía asumir los gastos que generaba la práctica de una prueba, cuando estos obedecían a trámites administrativos de personal y maquinaria que le generaban costos al particular que los presta, lo que necesariamente tenía que trasladar a la persona que requiere el servicio. La historia terminó cuando el cementerio decidió hacer una ostensible rebaja de los costos del procedimiento de 
exhumación y se pudo realizar el procedimiento. ${ }^{8}$

Como pudimos observar en el anterior caso jurisprudencial, si bien la prueba de exhumación iba a ser realizada por peritos de medicina legal, el procedimiento requería de ciertos gastos (gastos de la pericia) materializados en el movimiento de tierra de manera técnica y especializada, para poder llegar hasta el féretro y tomar la respectiva muestra de los despojos mortales del padre del niño. Como efectivamente no existe un rubro presupuestal para asumir estos gastos con cargo al amparo de pobreza, debía asumirlos el amparado.

Las preguntas que surgen siguiendo con el caso real serían: ¿Y si la madre efectivamente no tuviera dinero para ofrecerle al cementerio?, ¿y si el cementerio no hubiese accedido a realizar alguna concesión económica?, ¿qué sería de los derechos fundamentales del niño, entre ellos, el derecho a la vida (piénsese en asuntos de alimentos o de derechos sucesorales que generan patrimonio necesario para la subsistencia del niño), el derecho a tener una familia, el derecho a la seguridad social, etc.?

¿Puede una persona de escasos recursos económicos, que no tenga cómo asumir este tipo de gastos, dejar en suspenso sus derechos o eventualmente renunciar a ellos, aun tratándose de derechos fundamentales, porque no existe un efectivo acceso a la administración de justicia? ¿Qué sentido tiene plantear el reconocimiento formal de derechos, si finalmente no pueden hacerse valer en la práctica? 0 dicho de otra forma, si la situación de pobreza es un impedimento efectivo para el ejercicio de un derecho, por su costo, esto puede motivar que el titular del derecho postergue su reconocimiento o renuncie a su defensa por atender otras necesidades de mayor importancia (Pareja y Álvarez, 2000).

Pero no solo es cuestionable que en sí la figura no contemple soluciones a este tipo de obstáculos, sino también la actitud pasiva e indiferente de los mismos organismos estatales, que dejan a merced de la caridad ciudadana su salida, actitud que no corresponde a los fines del Estado, especialmente en casos de debilidad manifiesta.

La solución inmediata a este tipo de obstáculos sería la destinación de mayores recursos económicos, pero desafortunadamente la gran crisis de la justicia pasa por esta misma falta de recursos en general. Pero si ellos pudieran llegar, considero indicado apropiar una partida con destinación específica a la asistencia jurídica de las personas de escasos recursos

8. Como el asunto terminó ahí, la Corte técnicamente no tomó ninguna decisión. No obstante precisó: "Así entonces, es cierto que el derecho de acción en condiciones de igualdad se encuentra regido por el principio de la gratuidad, en el sentido de que los costos de la función pública de administrar justicia son asumidos por el erario público, pues se trata de una función de interés general en la medida en que es el Estado a quien corresponde brindar a los ciudadanos reales posibilidades de resolución de sus conflictos. Otra cosa, son los costos que se generen en el trámite de una actuación administrativa o privada de un proceso judicial hasta obtener una decisión definitiva, los cuales deben ser asumidos por la parte interesada, como se hizo en este caso, en proporción a su nivel económico, tal como lo decidió la empresa accionada". 
inmersas en procesos judiciales. $Y$ no es imposible, de hecho ya en Colombia existen experiencias donde efectivamente el amparo de pobreza cubre gastos de la pericia. ${ }^{9}$ La Ley 472 de 1998, que regula las acciones populares y de grupo, en su artículo 19 expresa:

El juez podrá conceder el amparo de pobreza cuando fuere pertinente, de acuerdo con lo establecido en el Código de Procedimiento Civil, o cuando el Defensor del Pueblo o sus delegados lo soliciten expresamente.

Parágrafo.- El costo de los peritazgos, en los casos de amparo de pobreza, correrá a cargo del Fondo para la Defensa de los Derechos e Intereses Colectivos, a partir de su creación. Estos costos se reembolsarán al Fondo por el demandado, en el momento de satisfacer la liquidación de costas, siempre y cuando fuere condenado. [Cursivas fuera de texto].

De esta forma, un rubro presupuestal de tal importancia tendría un fundamento: la protección del efectivo acceso a la justicia y la garantía de igualdad procesal de las personas de más escasos recursos como imperativos constitucionales. Considero, entonces, que para que ello pueda funcionar es necesario modificar la figura, por ejemplo, exigiendo pruebas para acreditar la condición de pobre, con la finalidad de que en mayor medida sus beneficios sean concedidos a las personas que verdaderamente los necesitan. De lo contrario, como he comentado, ante la laxitud en su concesión personas inescrupulosas o que verdaderamente no lo necesitan, podrían abusar de los beneficios en detrimento de otros ciudadanos.

\section{El abogado de oficio}

Esta es una de las mayores prerrogativas del amparo de pobreza sin duda alguna, pues en sus manos y conocimiento está gran parte del éxito de la figura para aquellos a quienes les ha sido concedida, ya que en el abogado reposa el ejercicio de la defensa técnica. La función social del abogado es inherente a su profesión; en ella radica, precisamente, el hecho de ser el defensor de los derechos ajenos, y constituye uno de los elementos centrales para su materialización. Guzmán de Lázaro afirma que de las

trascendentes funciones que la abogacía cumple en la sociedad, es lo cierto que, desde antiguo, una de las paradigmáticas y fácilmente perceptibles por la ciudadanía es la asunción de la defensa de las personas que carecen de posibilidades económicas para ello. (2008, p. 35).

El artículo 155 CGP establece que en la providencia que conceda el amparo, el juez designará el apoderado que represente en el proceso al amparado, salvo que aquel lo haya designado por su cuenta; y que el cargo de apoderado será de forzoso desempeño. También, que el abogado designado deberá manifestar su

9. Pero no existe en las siguientes materias: civil, familia, laboral y administrativo. 
aceptación o presentar prueba del motivo que justifique su rechazo.

¿Cómo se elige? En la anterior legislación se exigía que cada juez elaborara un listado de los abogados que litigaban en su despacho, y de ella, se fueran designando para atender la defensa de los amparados. Esa lista nunca se llevaba en la práctica, por lo que seguramente motivó que el actual CGP eliminara esta disposición. De esa forma la designación quedó en manos del juez de conocimiento (como siempre lo ha sido), quien podrá nombrar a cualquier abogado que litigue en su despacho.

Como consecuencia, de ser concedido el amparo de pobreza, el favorecido no está en la obligación de pagar los honorarios del abogado. De todas formas, en caso que la sentencia sea favorable al amparado, corresponderá al abogado de oficio las agencias en derecho que el juez señale a la parte contraria. Igualmente, si el amparado obtiene provecho económico en razón del proceso, deberá pagar al apoderado el $20 \%$ de tal provecho si el proceso fuere declarativo o el $10 \%$ en los demás casos.

Pese a la bondad de la prerrogativa, en la práctica ha tenido algunos reparos. Por ejemplo, es un hecho conocido que los abogados de oficio normalmente reciben como honorarios tasas muy bajas con respecto a las que recibirían frente a un caso particular; además, se trata de un pago aleatorio (piénsese en si el amparado pierde el proceso, ambas partes están amparadas por pobres, o el proceso no involucra pagos de dinero), por lo que pese a que exista vocación de servicio, esta situación puede afectar su motivación y, como consecuencia, una eventual e inadecuada defensa técnica para el amparado.

Algunos han sostenido la inconstitucionalidad de la figura, toda vez que supone la violación de un conjunto de garantías constitucionales, como la igualdad ante la ley y la igualdad de repartición de las cargas públicas; pues supone trabajo no remunerado para los abogados que ejercen libremente la profesión. (Espejo, 2008, p. 200).

Además, en sistemas como la defensoría pública que es propia en materia penal, los defensores que cumplen similar trabajo ${ }^{10}$ al de los abogados de oficio en las demás áreas del derecho sí perciben remuneración fija por sus servicios (Ley 941 de 2005).

Inclusive, puede generar cargas para algunos abogados, paradójicamente, de escasos recursos. El Consejo Superior de la Judicatura (Jurisdiccional, 12 nov. 2014, N. Osuna), conoció de un caso donde se denunció a un abogado por no acudir a una audiencia en materia penal. El abogado se dedicaba a la defensa de personas de escasos recursos, y no tenía ingresos suficientes para los gastos de traslado al lugar donde se desarrolló una diligencia penal. El

10. La defensoría pública es gratuita y se prestará en favor de aquellas personas que se encuentren en imposibilidad económica de proveer la defensa de sus derechos, con el fin de asumir su representación judicial. 
Consejo Superior de la Judicatura lo absolvió argumentando: "El abogado disciplinado ejerce en condiciones de notoria estrechez económica, que se reflejan en la precaria infraestructura física con la que cuenta para atender a sus clientes e incluso en la muy modesta cuantía de los honorarios que percibe".

Por otro lado, también se echan de menos criterios y procedimientos para la selección de los abogados de oficio, razón que puede generar desigualdades tanto para los abogados como para los usuarios. Además, se trata de una figura que no contempla instancias de seguimiento y evaluación de la gestión desempeñada, lo que puede desincentivar la buena atención a los beneficiados. ${ }^{11}$ Por ejemplo, es muy diferente la forma como ejercen la labor los abogados de oficio, a la de los defensores públicos en materia penal; los primeros pueden funcionar como "ruedas sueltas", mientras que los segundos pertenecen a todo un sistema nacional que ejerce control y les brinda capacitación y asistencia técnica.

También, la figura del abogado de oficio puede ser de difícil acceso para ciudadanos de escasos recursos que residan en municipios y zonas rurales apartadas de las urbes, que es donde generalmente se encuentran las personas con menos recursos económicos. Por lo que si se designara uno que ocasionalmente pasara por allí, este justificadamente podría negarse a ejercer el cargo, tal como se deduce de la misma legislación. ${ }^{12}$ En este sentido, se justificaría la creación de una institución de defensoría pública en otras áreas del derecho diferentes a la penal, que cubriera la carencia de abogados de oficio aunque fuera en estas zonas remotas.

Finalmente, la Ley 583 del 2000 es la que regula actualmente la práctica jurídica de los consultorios jurídicos del país, donde los estudiantes de los dos últimos años de derecho, conforme a la ley, actuarán como "abogados de pobres". Sin lugar a dudas, una de las mejores experiencias en la formación del futuro abogado es la práctica en el consultorio jurídico, pues allí el estudiante tiene su primer contacto con los usuarios y, además, tiene la oportunidad de poner en práctica sus conocimientos académicos y aprender su vocación de servicio social.

Pero no podemos olvidarnos que se trata de estudiantes de derecho, no de abogados, y aunque estén directamente asesorados por profesores abogados, el asunto es asumido directamente por el estudiante, lo que unido a la comprensible falta de experiencia profesional y a la variedad de asuntos que conocen, es de-

11. Su vigilancia está en cabeza del Consejo Superior de la Judicatura, por denuncia que pueda ser instaurada por un juez o por la parte afectada por la actuación irregular del abogado.

12. Artículo 154 CGP. El cargo de apoderado será de forzoso desempeño y el designado deberá manifestar su aceptación o presentar prueba del motivo que justifique su rechazo... Si el apoderado no reside en el lugar donde deba tramitarse la segunda instancia o el recurso de casación, el funcionario correspondiente procederá en la forma prevista en este artículo a designar el que deba sustituirlo. 
cir, la falta de especialidad, incide en la calidad de los servicios prestados.

También, la temporalidad de la práctica vs. la duración de un proceso judicial en Colombia hace que un asunto pueda pasar por manos de varios estudiantes, generando deficiencias en el trámite, un efecto negativo en la atención de los usuarios y, por ende, en la eficacia de los servicios. Igualmente, en las épocas de vacaciones estudiantiles no coincidentes con la vacancia judicial, la falta de control sobre el estudiante también podría incidir negativamente en los intereses del litigante pobre; inclusive hay que tener en cuenta que técnicamente volvería a ser estudiante solo hasta que se matricule en el siguiente semestre. Además, en aquellos consultorios jurídicos que prestan servicios descentralizados en municipios y veredas lejanas, si representan a la parte no podrán representar a la contraparte aunque también esté en las mismas condiciones de pobreza, debido a un eventual conflicto de intereses.

\section{CONCLUSIONES}

En Colombia los derechos de acceso a la justicia y de igualdad son protegidos a partir de instrumentos internacionales como la Convención Americana sobre Derechos Humanos, y de normas nacionales con base en lo que pregona la Constitución Política. En ese orden de ideas, el amparo de pobreza es condición sine qua non para la tutela de los derechos fundamentales de acción e igualdad de las personas de escasos recursos, por lo que las deficiencias en la estructura legal y en la aplicación fáctica de la figura los pueden dejar en grave peligro de no materialización.

El concepto de "pobre" en el amparo de pobreza es equívoco y restrictivo, pues da a entender que solo personas en estado de indigencia pueden solicitar este beneficio. Por ello se invita a entender que para su concesión, el solicitante deberá demostrar la carencia de recursos y la imposibilidad de obtenerlos, y por ende, que no puede afrontar las erogaciones que demande el proceso, permitiendo inclusive que personas que se encuentran dentro de la llamada "clase media" puedan eventualmente solicitar dicho amparo.

Pese a que la definición de amparo de pobreza al especificar que se trata de que "el interviniente no se vea forzado a escoger entre atender su congrua subsistencia y la de las personas a quienes por ley debe alimentos" da a entender que el beneficio se concede a personas naturales, realmente debe interpretarse que las personas jurídicas también tienen derecho a este cuando se encuentren en situaciones de manifiesta debilidad económica. Con todo, es necesario estudiar la verdadera situación económica y financiera de la empresa, a partir de pruebas propias de estas instituciones, tales como: balances, estados contables, pasivos internos y externos, etc.

Aunque discutible dentro de la jurisprudencia nacional (lo que ya de entrada hace caótica su interpretación), la prueba de la calidad de "pobre" no se exige, lo que hace que en ocasiones 
se otorgue de manera irrestricta sin consultar la verdadera necesidad del solicitante, afectando por consiguiente intereses de terceros, al paso que puede coadyuvar a la carga y congestión de los despachos judiciales. Por lo anterior propongo que para acceder al beneficio no baste con la afirmación del solicitante sobre su situación de pobreza, sino que deba probarlo aunque sea sumariamente, invirtiendo la presunción legal que hoy en día mantiene la legislación procesal.

El Estado colombiano no destina recursos para la materialización de la figura, de suerte que los beneficios económicos que pueda recibir el amparado corren directamente a cargo de otros ciudadanos. Igualmente, existen gastos dentro del proceso judicial que deben costearse directamente por el amparado pues no son asumidos ni por el Estado ni por terceros, y al no poder asumirlos pone en riesgo sus derechos, por lo que es claro que en Colombia las limitaciones económicas sí son un obstáculo para acceder a la justicia. La solución inmediata a este tipo de obstáculos sería destinar mayores recursos económicos dentro del presupuesto general de la justicia, asignando rubros con destinación específica a la asistencia jurídica de las personas de escasos recursos inmersas en procesos judiciales.

La elección, control y vigilancia de los abogados de oficio no están sujetos a parámetros claros, ni existen instancias de seguimiento y evaluación de la gestión por ellos desempeñada, por lo que es necesario crear un sistema general de defensoría similar al que hoy se contempla en materia penal, donde los defensores tienen control, y reciben capacitación y asistencia técnica.

Los servicios de los abogados de oficio son extraños a poblaciones alejadas de las medianas y grandes ciudades debido a la insuficiente disponibilidad de abogados. En este sentido se justificaría la creación de una institución de defensoría pública en otras áreas del derecho diferentes a la penal, que cubra la carencia de abogados de oficio en zonas remotas del país.

\section{Referencias}

1. Caso Baldeón García vs. Perú. [Corte Interamericana de Derechos Humanos]. (2006). Fondo, reparaciones y Costas (abril 6 de 2006).

2. Caso Cantos vs. Argentina. [Corte Interamericana de Derechos Humanos]. (2002). Fondo, Reparaciones y Costas (noviembre 28, 2002).

3. Congreso de la República de Colombia. (12 de junio de 2000). Ley 583 del 2000. Por la cual se modifican los artículos 30 y 9 del Decreto 196 de 1971.

4. Congreso de la República de Colombia. (14 de enero de 2005). Ley 941 de 2005. "Por la cual se organiza el Sistema Nacional de Defensoría Pública".

5. Congreso de la República de Colombia. (5 de agosto de 2005). Ley 472 de 1998. Por 
la cual se desarrolla el artículo 88 de la Constitución Política de Colombia en relación con el ejercicio de las acciones populares y de grupo y se dictan otras disposiciones.

6. Consejo de Estado. Sección Cuarta. Auto. Expediente 25000232700020010695 0112701 de 2002 (C. P.: Juan Ángel Palacio Hincapié; febrero 1 de 2002).

7. Consejo de Estado. Sala de lo Contencioso Administrativo. Sección Cuarta. Auto. Radicación No. 25000-23-27-000-200601305-01(16313) (C. P.: Ligia López Díaz; mayo 3 de 2007).

8. Consejo de Estado. Sala de lo Contencioso Administrativo. Sección Cuarta. Auto. Radicación No. 54001-23-31-000-201200281(19966). (C. P. Carmen Teresa Ortiz de Rodríguez; abril 17 de 2013).

9. Consejo Superior de la Judicatura. Sala Jurisdiccional Disciplinaria. Radicación No. 73001110200020100027901 (M. P.: Néstor Iván Osuna Patiño; noviembre 12 de 2014).

10. Corte Constitucional de Colombia. Sentencia T-173 de 1993 (M. P.: José Gregorio Hernández Galindo; mayo 4 de 1993).

11. Corte Constitucional de Colombia. Sentencia T-268 de 1996 (M. P.: Antonio Barrera Carbonell; junio 18 de 1996).
12. Corte Constitucional de Colombia. Sentencia T-861 de 1999 (M. P.: Carlos Gaviria Díaz; octubre 28 de 1999).

13. Corte Constitucional de Colombia. Sentencia C-388 de 2000 (M. P.: Eduardo Cifuentes Muñoz; abril 5 de 2000).

14. Corte Constitucional de Colombia. Sentencia C-1027 de 2002 (M. P.: Clara Inés Vargas Hernández; noviembre 27 de 2002).

15. Corte Constitucional de Colombia. Sentencia T-114 de 2007 (M. P.: Nilson Pinilla Pinilla; febrero 22 de 2007).

16. Corte Constitucional de Colombia. Sentencia T-680 de 2007 (M. P.: Marco Gerardo Monroy Cabra; agosto 30 de 2007).

17. Corte Constitucional de Colombia. Sentencia T-356 de 2009 (M. P.: Gabriel Eduardo Mendoza Martelo; mayo 20 de 2009).

18. Corte Suprema de Justicia. Sala laboral. Expediente No. 28748 de 2006 (M. P.: Isaura Vargas Díaz; febrero 8 de 2006).

19. Corte Suprema de Justicia. Sala de Casación Penal. Expediente No. 36420 de 2011 (M. P.: Julio Enrique Socha Salamanca; junio 8 de 2011).

20. Corte Suprema de Justicia. Sala Laboral. (M. P.: Rigoberto Echeverry Bueno; diciembre 11 de 2013). 
21. Devis Echandía, H. (1978). Compendio de derecho procesal. (Tomo III). Bogotá: ABC.

22. Espejo Yaksic, N. (2008). Informa anual sobre derechos humanos en Chile 2008. Santiago de Chile: Facultad de Derecho Universidad Diego Portales.

23. Guzmán de Lázaro, L. N. (2008). Turno de Oficio y Justicia Gratuita. Madrid: La Ley.

24. Instituto de Defensa Legal de Perú, Fundación Debido Proceso Legal, Centro de Derechos Humanos en las Américas de la Universidad De Paul (Chicago), Centro de Derechos Humanos y Asesoría a Pueblos Indígenas de México y Centro de Estudios sobre Justicia y Participación de Bolivia. (2008). Barreras para el acceso a la justicia en América Latina. Audiencia ante la Comisión Interamericana de Derechos Humanos. Washington D. C.

25. López Blanco, H. F. (2005). Procedimiento Civil (t. I). Bogotá: Dupré Editores.

26. Morales Molina, H. (1991). Curso de derecho procesal civil: parte general. Bogotá: Editorial ABC.
27. Palacio, L. E. (1977). Manual de Derecho Procesal Civil. Buenos Aires: Abeledo-Perrot.

28. Pareja, G. G. y Álvarez Pérez, V. (2000). Pobreza y administración de justicia. Revista de la Facultad de Ciencias Económicas, (5), 101-118.

29. Parra Quijano, J. (2004). Manual de Derecho Probatorio. Bogotá: Librería Ediciones del Profesional Ltda.

30. Ventura Robles, M. E. (4 de 2 de 2015). La jurisprudencia de la Corte Interamericana de Derechos Humanos en materia de acceso a la justicia e impunidad. Recuperado de: http://www.corteidh.or.cr/tablas/ r31036.pdf

31. Rodríguez Saiach, L. A. y Knavs, V. (2007). Beneficio de litigar sin gastos. Buenos Aires: La ley.

32. Semana. (16 de mayo de 2015). Colombia, un país de clase media. Obtenido de Semana: http://www.semana.com/nacion/ articulo/colombia-un-pais-de-clase-media/427747-3. 